\title{
ANTIOXIDANT ACTIVITY TEST OF ANDROGRAPHOLIDE IN BITTER HERBS USING DPPH SCAVENGING
}

\author{
${ }^{1}$ Department of Pharmacy, Faculty of Mathematics and Natural Sciences, Udayana University, Bukit Jimbaran, \\ Badung Telp/Fax : 0361 224133, \\ dekpitsusanti@unud.ac.id
}

\section{Ni Made Pitri Susanti ${ }^{1}$, Ni Kadek Warditiani ${ }^{1}$, I Made Agus Gelgel Wirasuta ${ }^{1}$}

\begin{abstract}
Bitter herbs (Sambiloto) have many pharmacological activities including antioxidant, antidiabetic, anticancer, antihyperlipidemic and anti-inflammation. Andrographolide is a diterpene compounds contained in bitter herbs. It is known that andrographolide compound responsible for the pharmacological activity of the bitter herbs. This study investigated DPPH free radical scavenging activity from andrographolide diterpene lactone. This study was initiated with the isolation of andrographolide compound from bitter herbs and then testing their DPPH free radical scavenging. The results suggested that andrographolide had $\mathrm{IC}_{50}$ value of $5.45 \mathrm{mg}$. This means andrographolide has 50\% DPPH inhibition effect, i.e $5.45 \mathrm{mg}$.
\end{abstract}

Keywords: andrographolide, antioxidant, bitter herbs, DPPH, free radical

\section{INTRODUCTION}

In our environment, there are many sources of free radicals which cannot be avoided. Among them are motor vehicle fumes, cigarette smoke, food fried in cooking oil, baked foods, certain drugs, and air pollution. Free radical is a molecule having one or more unpaired electrons. These free or unpaired electron is highly reactive to the body's cells. This suggests that the cells in our bodies are oxidized [1], [2].

The presence of free radicals in the body that lead to oxidation reaction will cause damage to the nucleic acids, fat and DNA cell. This event will initiate the occurrence of degenerative diseases such as memory loss, cataracts, cancer and cardiovascular disorders [1], [3]. Our body has ability to protect cells against oxidation reactions that may occur in the presence of peroxidase, catalase, glutathione, histidine-peptidine. More over, the intake of foods containing antioxidants can also protect our body against free radical attack. Consumption of foods such as fruits and vegetables, contain antioxidants compounds like vitamins A (beta-carotene), C and E [4].

Secondary metabolites contained in the plant have potential effect as free radical scavenger such as carotene, lycopene, polyphenols and flavonoids [5], [6]. The main mechanism of antioxidant compounds from secondary metabolites contained in the plant is the capability to bind, stabilize and prevent free radicals and not damage the body's cells [5].

Dragon fruit (Hylocereus undatus (Haw.) Britt. \& Rose; Cactaceae family) contains vitamin $\mathrm{C}$ and carotene that have potential antioxidants. Based on the research of DPPH free radical in methanol and water extracted from dragon fruit, $4.49 \%$ of water extract (equivalent to $3.08 \mathrm{~g}$ of fresh dragon fruit) has the ability to scavenge free radicals by
$87.11 \%$ in the 5 th minute and $90,83 \%$ in the 30th minute; while $6.47 \%$ of methanol extract (equivalent to $4.44 \mathrm{~g}$ fresh dragon fruit) have the ability to scavenge free radicals by $79.18 \%$ in the 5 th minute and 90.46 in the 30th minute. $\mathrm{EC}_{50}$ value of the water extract is $1.08 \%$. Bitter herbs (sambiloto) play a role as an antioxidant against free radicals oxidative damage. Reference [7] suggested that the methanol extract of bitter herb (Andrographis paniculata) inhibit DPPH free radicals so they have an antioxidant potential. Inhibition of DPPH free radicals measurement by this bitter methanol extract is compared with gallic acid. But the study did not calculate the $\mathrm{IC}_{50}$ value. Thus, it is important to measure inhibition of DPPH free radicals from andrographolide compound of bitter herbs and calculate the $\mathrm{IC}_{50}$ value. The $\mathrm{IC}_{50}$ value is the concentration of a compound that shows an ability to inhibit free radicals by $50 \%$.

\section{METHODS AND PROCEDURE}

\section{A. Bitter Herbs Preparation}

Bitter herbs obtained is dried then downsized to simplify and accelerate the extraction. Dried process is to reduce the water content in bitter herbs to prevent damage to the herbs. Damage herbs can be triggered by the growth of microbes or fungi and the enzymatic reaction due to high water content.

\section{B. Extraction and Isolation}

Bitter herbs powder was extracted with $96 \%$ ethanol by maceration method for 24 hours. After 2 times re- 
maceration by using the same solvent, evaporation of the solvent in order to obtain a thick extract was done. Condensed extract of bitter herbs re-extracted with a $n$ hexane solvent to remove chlorophyl which were contained in the ethanol extract of bitter herbs. We separated the non soluble part in $n$-hexane. The process was continued with extract purification process in order to obtain purified extract. Re-cristalization was done by dissolving the purified extract in hot methanol, and then cooling until it formed crystals andrographolide.

\section{DPPH Level Measurement}

Samples were prepared by weighing $10 \mathrm{mg}$ of extract and dissolved in $1 \mathrm{~mL}$ of pro analysis methanol. An amount of $200 \mu \mathrm{L}$ then was added with $1800 \mu \mathrm{L}$ methanol. From this solution then pipette 100, 300, 500, 700 and $900 \mu \mathrm{L}$, respectively added by methanol to a series volume of $1 \mathrm{~mL}$. Each sample was pipetted $500 \mu \mathrm{L}$ and was added with 500 $\mu \mathrm{L}$ DPPH, incubated for 1 hour. DPPH crystals were dissolved in ethanol to get a concentration of $0.025 \%$ in methanol for immediate use and kept in light-protected low temperature.

Samples were then spotted on a TLC plate of silica gel GF 254. Plate was scanned at a wavelength of $530 \mathrm{~nm}$.

\section{IC50 Measurement}

Inhibition of free radicals was calculated based on the result of reduction in area under the curve (AUC) forms by the sample AUC toward AUC at a wavelength of $530 \mathrm{~nm}$ using a calculation as refer to (1).$$
\frac{(\text { AUCblanko-AUCsample })}{\text { AUCblanko }} \times 100 \%
$$

\section{RESULTS AND DISCUSSION}

Based on andrographolide isolation results, obtained andrographolide crystals was amorphous as shown in Fig. 1. Visible light spectra profile of andrographolide in various levels and DPPH solution can be seen in Fig. 2.
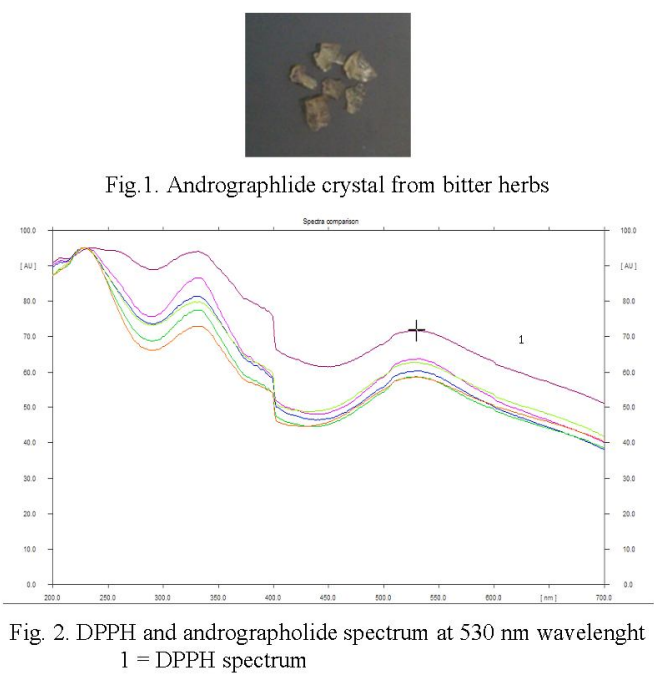

Andrographolide levels in extract were quite a lot. Extraction using $n$-hexane was able to eliminate non-polar compounds compared to andrographolide chlorophyll. Andrographolide effect on inhibit DPPH was tested by adding andrographolide and reagents DPPH and performed incubation for 1 hour. Appropriate incubation time is very important note to get the value of AUC and a good spectrum at a $530 \mathrm{~nm}$ wavelength, maximum wavelenght for DPPH. Test for free radical scavenging begins with making spectrum in the range of $400-600 \mathrm{~nm}$ visible light from DPPH solution and andrographolide. This measurement is done to look at the pattern of the blank DPPH and DPPH added andrographolide spectrum.

Measurements were made by looking at the value of AUC (Area Under the Curve) contained at a $530 \mathrm{~nm}$ wavelength. The AUC values result from the blank DPPH and DPPH added andrographolide shown in Table 1.

Table 1.

AUC Value from Blank DPPH and Andrographolide

\begin{tabular}{ccccccc}
\hline No & Blank & $50 \mu \mathrm{g}$ & $150 \mu \mathrm{g}$ & $250 \mu \mathrm{g}$ & $350 \mu \mathrm{g}$ & $450 \mu \mathrm{g}$ \\
\hline 1 & 7430,5 & 6304,5 & 6799,7 & 6483,7 & 6266,3 & 6293,0 \\
2 & 7522,5 & 6209,6 & 6473,3 & 6451,5 & 6198,0 & 6149,0 \\
3 & 7074,0 & 6634,7 & 6288,6 & 6371,1 & 6402,8 & 6277,4 \\
4 & 7463,9 & 6680,4 & 6185,7 & 6416,5 & 6486,8 & 6230,4 \\
\hline
\end{tabular}

The smaller the value of AUC in addition of andrographolide showed greater andrographolide concentrations was added. Conversely, increase andrographolide concentration was added, will increase the $\%$ inhibition of DPPH free radicals. The result of percentage inhibition calculation can be seen in Table 2 .

According to Table 2, an equation to calculate the $\mathrm{IC}_{50}$ value of andrographolide was created. The calculation of $\mathrm{IC}_{50}$ was done by interpolarized percent reduction $(50 \%)$ in the test solution concentration curve with the percent reduction. Andrographolide concentration and the percent reduction data obtained regression curve as in Fig. 3.

Table 2.

DPPH Inhibition from Andrographolide Compound

\begin{tabular}{cccccc}
\hline \multirow{2}{*}{ No } & \multicolumn{5}{c}{$\%$ Free Radical Inhibition } \\
\cline { 2 - 6 } & $50 \mu \mathrm{g}$ & $150 \mu \mathrm{g}$ & $250 \mu \mathrm{g}$ & $350 \mu \mathrm{g}$ & $450 \mu \mathrm{g}$ \\
\hline 1 & 14,489 & 7,772 & 12,058 & 15,007 & 14,645 \\
2 & 15,776 & 12,199 & 12,495 & 15,933 & 16,598 \\
3 & 10,010 & 14,705 & 13,586 & 13,156 & 14,856 \\
4 & 9,390 & 16,100 & 12,970 & 12,016 & 15,494 \\
Mean & 12,416 & 12,694 & 12,777 & 14,028 & 15,398 \\
SD & 3,190 & 3,657 & 0,655 & 1,770 & 0,877 \\
\hline
\end{tabular}




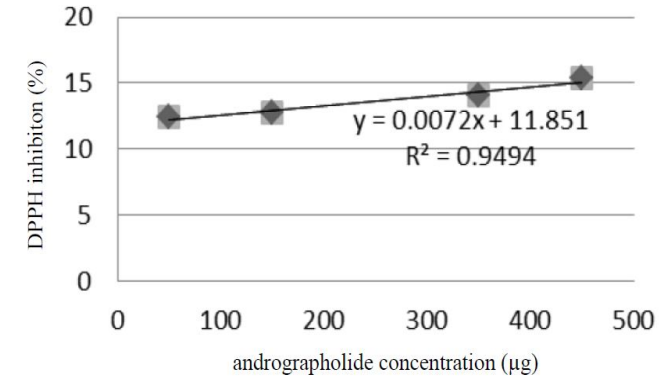

Fig. 3. Percentage of DPPH inhibition and andrographolide concentration $(\mu \mathrm{g})$

Based on \% DPPH inhibition and andrographolide concentration $(\mu \mathrm{g})$ corelation curve, a straight-line equation, namely $\mathrm{y}=0,007 \mathrm{x}+11.85$ was constructed. The value of $\mathrm{y}$ is \% DPPH inhibition, while the value of $\mathrm{x}$ is andrographolide concentration. Based on calculations, andrographolide $50 \%$ inhibition or $\mathrm{IC}_{50}$ is $5.45 \mathrm{mg}$. A value of $0 \%$ means that the compound does not have a free radical or antioxidant activity, while a value of $100 \%$ means a total reduction of a compound.

\section{CONCLUSION}

Andrographolide compounds can be separated from bitter herbs by re-crystallization. $\mathrm{IC}_{50}$ value of $\mathrm{DPPH}$ radical inhibition by andrographolide is $5.45 \mathrm{mg}$.

\section{ACKNOWLEDGMENT}

The authors thank the Ministry of Research Technology and Higher Education and Udayana University for the opportunity to get competitive grant in 2016.

\section{REFERENCES}

[1] Pietta P-G., 1999. Flavonoids as Antioxidants, Reviews, J. Nat. Prod., 63, 1035-1042

[2] Wijaya A., 1996. Radikal Bebas dan Parameter Status Antioksidan, Forum Diagnosticum, Prodia Diagnostic Educational Services, No. 1 $: 1-12$.

[3] Leong L.P., Shui, G., 2001. An Investigation of Antioxidant Capacity of Fruits in Singapore Markets, Food Chemistry 76 : 69-75.

[4] Clarkson, P. M., Thompson, H. S. 2000, Antioxidants: what role do they play in physical activity and health, J. Clin Nutr. Biochem, 72.: 637S-46S.

[5] Prakash A., 2001. Antioxidant Activity, Medallion Laboratories Analytical Progress, Vol. 19 (2).

[6] Okawa M., Kinjo, J., Nohara, T., Ono, M., 2001. DPPH (1,1Diphenyl-2-Picrylhydrazyl) Radical Scavenging Activity of Flavonoids Obtained from Some Medicinal Plants, Biol. Pharm. Bull 24 (10), 1202-1205.

[7] Huidrom, Sangeeta and Deka, Manab, 2012, Determination of antioxidant property of Andrographis paniculata, IJDAD, 1(1): 1217 